Proc. Indian Acad. Sci. (Earth Planet. Sci.), Vol. 98, No. 3, October 1989, pp. 237-245.

(C) Printed in India.

\title{
Diffusion characteristics of the Kakinada Bay for effluent assessment
}

\author{
A S UNNIKRISHNAN and V ASTHANA* \\ Physical Oceanography Division, National Institute of Oceanography, Dona Paula 403 004, \\ India \\ * School of Environmental Sciences, Jawaharlal Nehru University, New Delhi 110067, India \\ MS received 27 February 1989; revised 18 September 1989
}

\begin{abstract}
The present study reports the determination of diffusion characteristics of the Kakinada Bay to choose a suitable marine outfall location for industrial discharge of effluents from a proposed fertilizer plant. The study consisted of dye diffusion experiments using Rhodamine-B, a fluorescent dye by the instantaneous release technique. Concentrations of samples collected at different time intervals were analysed using a fluorometer. Simultaneously, oceanographic data were also collected. The dye distributions were plotted based on the measured concentration values from the samples collected at various points in the patch. It was found that the movements of the patches depended on the tidal phase during the release. The computed values of diffusion coefficients were of the order of $0.2-2 \cdot 9$ $\times 10^{3} \mathrm{~cm}^{2} / \mathrm{s}$.
\end{abstract}

Keywords. Horizontal diffusion; Rhodamine-B; diffusion coefficients; Kakinada Bay.

\section{Introduction}

In marine pollution studies, choosing a suitable outfall location for industrial discharge of effluents is important to minimize ecological hazards. For this purpose, an understanding of the oceanographic conditions and dispersion characteristics of the environment is essential. Some of the methods to study these problems include development of diffusion and circulation models (Salomon 1980) and study of diffusion characteristics by experiments using dyes etc.

In the present paper, we discuss results of dye diffusion experiments conducted in the Kakinada Bay in order to choose a suitable outfall location for a proposed fertiliser plant. Dye diffusion was widely employed for such studies (e.g. Kullenberg 1968). The most commonly used dye is Rhodamine-B, the concentration of which can be measured in terms of its fluorescence. The present paper deals with the horizontal diffusion characteristics of the Bay, based on the results of release of Rhodamine-B and sampling of the dye patch developed.

\section{Area of observation}

The Kakinada Bay is situated along the east coast of India, about $160 \mathrm{~km}$ southwest of Visakhapatnam (figure 1). The freshwater input into the Bay is from two tributaries of Godavari, namely, the Coringa and the Gaderu. At the southwestern and southeastern corners, two creeks namely, the Matlapalem and Pillavara open into the Bay. On 
the eastern side of the Bay, there is a long narrow sand bar separating the bay from the Bay of Bengal.

\subsection{Hydrography}

The hydrography of the Kakinada Bay was studied by Rama Sarma and Ganapati (1968) and subsequently by others. These studies had shown that the Bay is a vertically homogeneous type during most part of the year, except during the (southwest) monsoon period when it is slightly stratified.

\subsection{Circulation}

According to Rama Sarma and Ganapati (1968), in addition to tides and local winds, one of the factors controlling the circulation in the Kakinada Bay is the coastal current, which runs along the east coast of India. The coastal current changes its direction seasonally, being southerly from August to December and northerly from January to July. Based on hydrographic data, Rama Sarma and Ganapati deduced the pattern of circulation inside the Bay as clockwise from December to June and counter-clockwise from July to November.

\section{Observations}

Dye diffusion experiments can be carried out in two different ways: (i) instantaneous release method and (ii) continuous release method. In the former, the dye is released at a point at an instant and concentrations measured in space at different intervals of time. In the latter technique, the dye is released at a continuous rate at a point and concentrations measured in space, once a steady state is reached.

\subsection{Rotationally symmetrical models}

In the present study, instantaneous release technique was used. In this method, after some time of release, the pattern of isolines of various concentrations in the distribution of dye patch will be irregular and the centre of mass need not coincide with maximum concentration. Now consider a large number of similar experiments to be conducted under identical oceanographic conditions with the same initial mass. After some time $t$, the distributions obtained need not be the same in each case. By superimposing all these distributions obtained about the centre-of-mass and averaging them, we get a rotationally symmetrical distribution in which concentration is a function of radius of the equivalent circle and time.

Okubo (1962) derived the differential equation for a rotationally symmetrical distribution as:

$$
\frac{\partial C}{\partial t}=\frac{1}{r} \frac{\partial}{\partial r}\left\{K r \frac{\partial C}{\partial r}\right\},
$$

where $r$ is the radius of the equivalent circle, $K$ the coefficient of diffusion, $M$ the concentration of the mass at the source during release, and $C$ the concentration at a point $t$. 
Different methods have been used to solve the above differential equation. When $K$ is assumed as constant, the solution becomes:

$$
C(r, t)=\frac{M}{4 \pi K t} \exp \left(-r^{2} / 4 K t\right)
$$

which is the simple Fickian-type solution, where $K$ is defined as the diffusion coefficient and expressed as $\mathrm{cm}^{2} / \mathrm{s}$. There are also other models for diffusion from a point source, for example, those due to Joseph and Sendner (1958) and Okubo (1962). In the present work, we restrict our discussion to the application of equation (2). Let $r_{1}$ and $r_{2}$ be the radii for a given distribution i.e., for the same $t$. Let $C_{1}$ and $C_{2}$ be the corresponding concentrations respectively. So, we can write from (2),

$$
C_{1} / C_{2}=\exp \left(\frac{1}{4 K t}\left(r_{2}^{2}-r_{1}^{2}\right)\right)
$$

This relationship can be used for computing $K$.

\subsection{Experiments}

Four points were chosen at different places in the Bay, near the mouth, for dye releases. These stations, namely, D-1, D-2, D-3, D-4 are shown in figure 1 . The experiments were conducted using two vessels, a mechanized boat and a smaller nonmechanized one.

The first experiment was conducted during flood tide at location D-1. The main vessel was anchored at the release station. An Aanderaa-type current meter was moored at the station. The Rhodamine-B solution was mixed with 2.5 litres of alcohol (in 1:5 ratio) and the solution diluted to 20 litres. The density of the solution was approximately $0.8 \mathrm{~g} / \mathrm{cc}$. The release was made by directly pouring the solution into the Bay. This method of injection took only a few seconds, hence it can be considered as instantaneous release. Using the smaller vessel, the patch was traced after some time of the release. Samples were collected from various points inside the patch by taking the boat along different cross-sections. The position of the boat was fixed using sextants, while taking samples each time. The distribution of concentration was similarly traced at two more time intervals.

Samples collected were analysed using a fluorometer. Similar experiments were also conducted in other locations D-2, D-3 and D-4. The number of samples collected varied depending on the size of the patch. For instance, for the largest patches formed among the four sets i.e., in the case of D-2, the number of samples collected was 14,15 and 10 respectively. In D-4, correspondingly, 7, 15 and 13 samples were collected. The wind data collected from the India Meteorological Department, Kakinada is given in table 1 . The plots of dye distribution at different time intervals are given in figure 2 . The fixing of points, where concentration values were measured, was done by using a standard computer program based on the readings of sextants.

In each set of experiments, isolines of concentration were drawn for different time intervals of observation. The area enclosed by these lines was graphically computed, from which the radius of the equivalent circle was calculated. Diffusion coefficients were computed by making use of equation (3) for every two successive concentration values. The computed values are shown in tables 2 to 3 . 


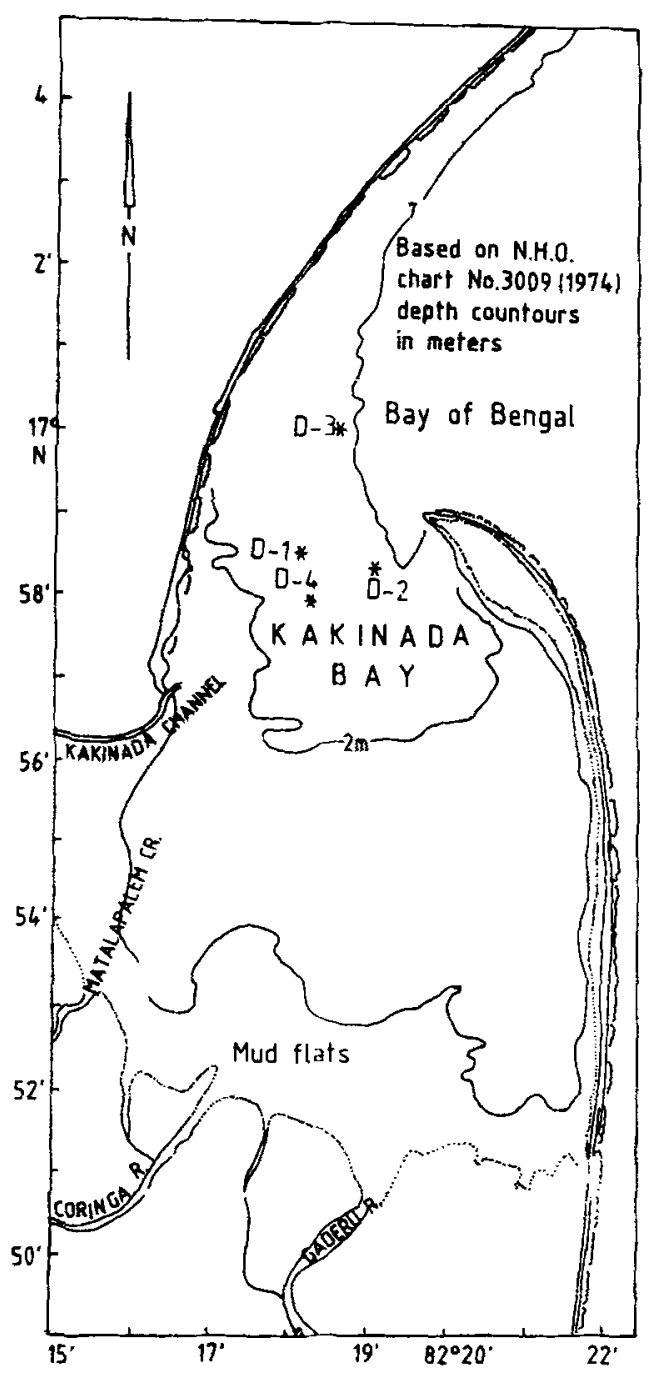

Figure 1. The Kakinada Bay. D-1, D-2, D-3 and D-4 are the dye release stations.

\section{Discussion}

Equation (3) was employed to evaluate the diffusion coefficients. The equation deals with horizontal diffusion and does not take into account the vertical velocity shear and its effect on horizontal diffusion. In a nearly vertically homogeneous type bay, such as the Kakinada Bay, it is assumed that vertical shear is negligible.

The current speed, direction and tidal elevations at the release points are also shown in figure 2. At D-1, no current measurements were made. Tidal ranges are not high in this region. They are of the order of about $0.5 \mathrm{~m}$. The magnitudes of currents are of $10-20 \mathrm{~cm} / \mathrm{s}$. The curves of current speed with time show some periodicities similar to the tidal curves, indicating the influence of tides on the circulation in this region.

Table 1 shows that the direction of wind was mostly southeasterly during all the 
Table 1. Wind data at Kakinada (India Meteorological Department).

\begin{tabular}{lrcl}
\hline & $\begin{array}{r}\text { Time } \\
\text { Station }\end{array}$ & $\begin{array}{r}\text { Wind } \\
\text { speed } \\
(\mathrm{km} / \mathrm{h})\end{array}$ & Direction \\
\hline D-1 & 19 & 6 & ESE to SE \\
& 50 & & \\
& 61 & & \\
D-2 & 44 & Calm & \\
& 104 & 1 & SE \\
& 162 & 2 & \\
D-3 & 40 & 4 & \\
& 82 & 4 & SE \\
& 135 & 5 & \\
D-4 & 26 & 4 & \\
& 68 & 3 & ESE \\
& 125 & 1 & WSE \\
\hline
\end{tabular}

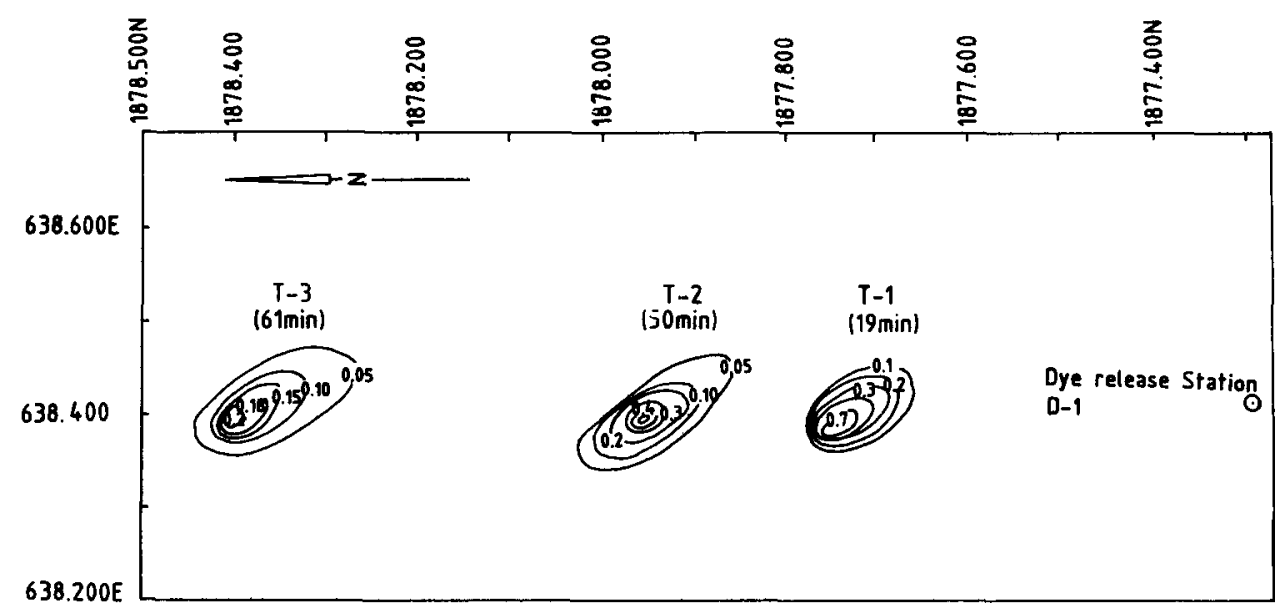

(2a)

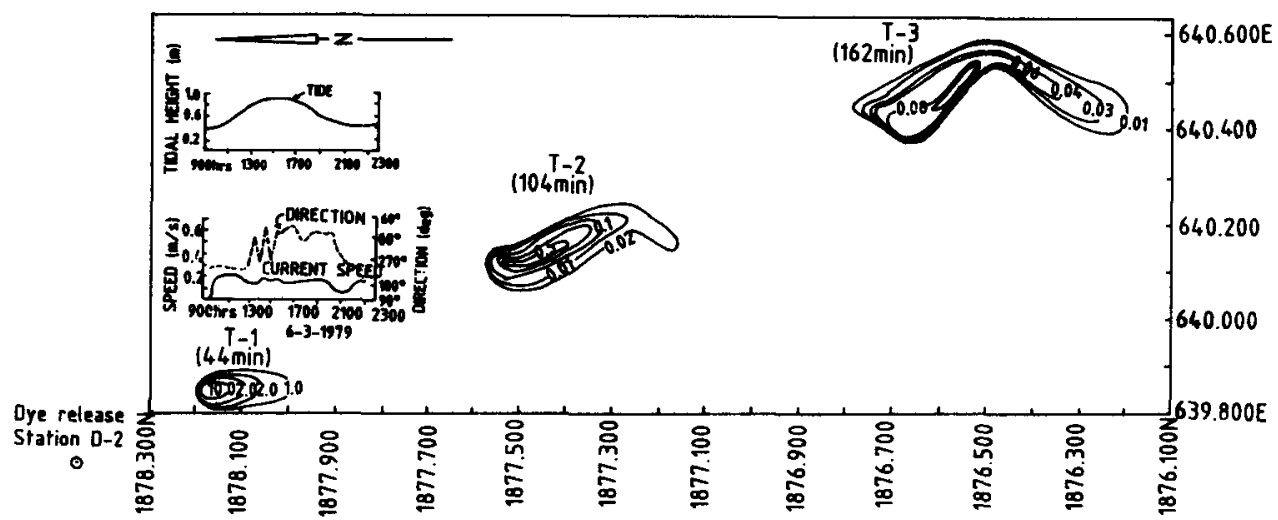

(2b) 


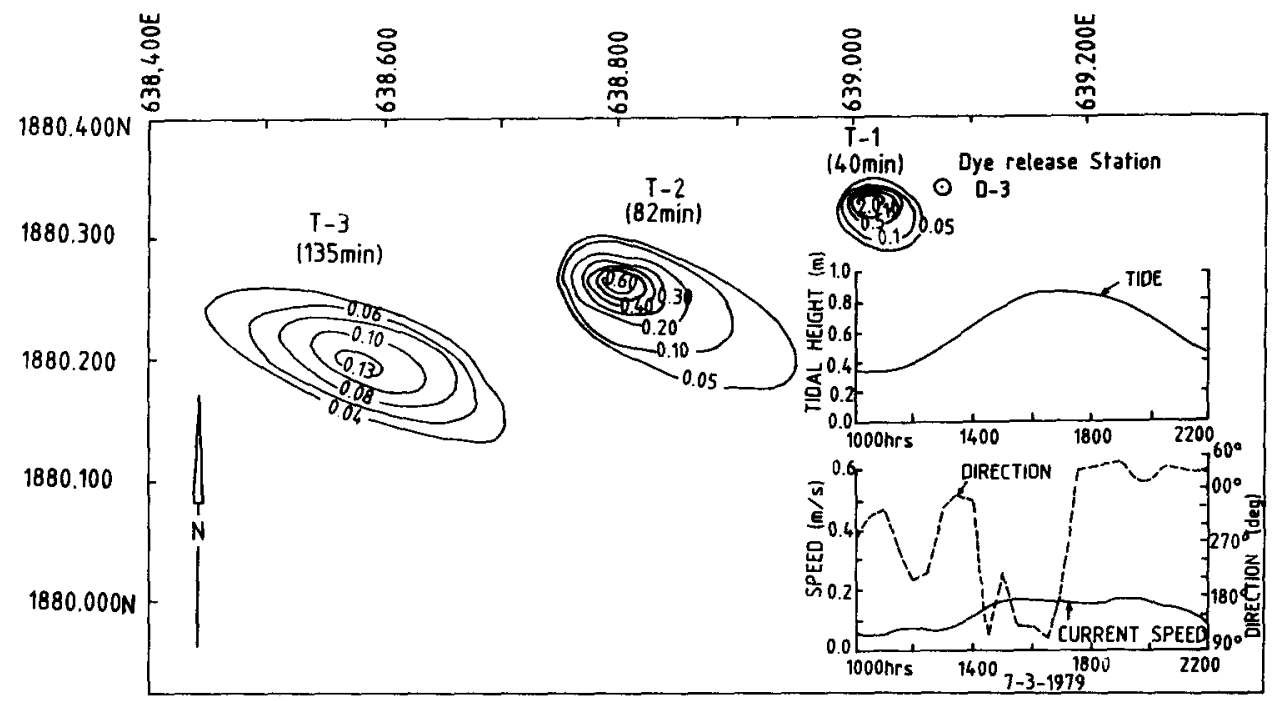

(2c)

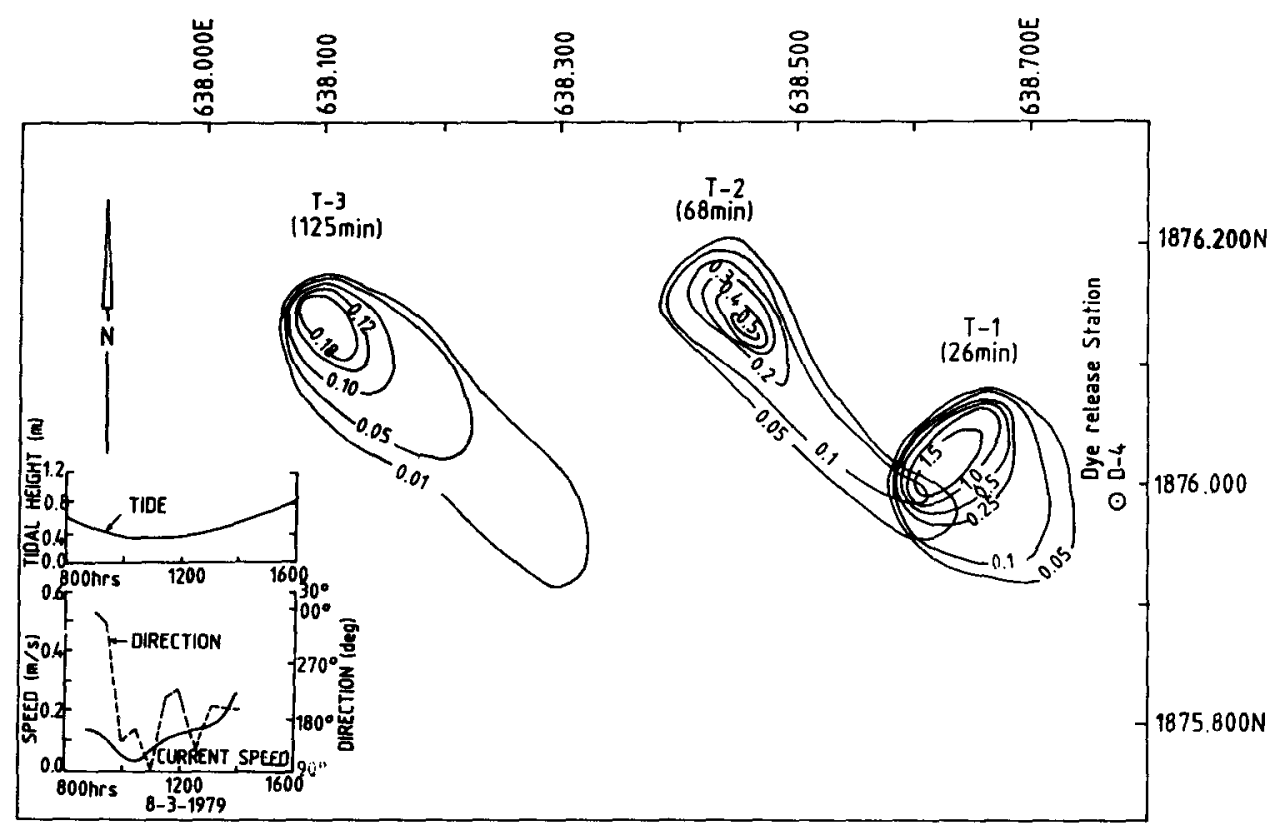

(2d)

Figure 2. Distribution of observed dye concentration. $N$ and $E$ shown along the axes represent northward and eastward directions respectively. The distances are given in $\mathrm{kms}$ in cither case. $1880.2 \mathrm{~N}$ corresponds to $17^{\circ} \mathrm{N}$ and $638 \cdot 11 \mathrm{E}$ corresponds to $82^{\circ} 18^{\prime} \mathrm{E}$. (a) Dye release station D-1, 5-3-79; (b) Dye release station D-2, 6-3-79; (c) Dye release station D-3, 7$3-^{\prime} 79$; (d) Dye release station D-4, 8-3-'79.

four experiments. The fact that the directions of movement of dye patches were not identical suggest that winds apparently did not affect their movements. Figure 2 indicates that the direction in which the dye patches got advected depended on the phase of the tide during their release and movement. For instance, at D-1, the release 
Table 2. Computed diffusion coefficients (expressed as $\mathrm{cm}^{2} / \mathrm{s}$ ) after the releases at D-1 and D-2.

\begin{tabular}{|c|c|c|c|c|c|c|c|}
\hline \multicolumn{4}{|c|}{$\begin{array}{l}\text { Release at D-1 } \\
\text { Initial mass released }=500 \mathrm{~g}\end{array}$} & \multicolumn{4}{|c|}{$\begin{array}{c}\text { Release at } \mathrm{D}-2 \\
\text { Initial mass released }=1000 \mathrm{~g}\end{array}$} \\
\hline $\begin{array}{l}\text { Concentration } \\
\text { (ppm) }\end{array}$ & $\begin{array}{l}\text { Time } \\
\text { (min) }\end{array}$ & $\begin{array}{l}\text { Radius } \\
\text { (m) }\end{array}$ & $\begin{array}{c}\text { Diffusion } \\
\text { coefficient } \\
\left(\times 10^{3} \mathrm{~cm}^{2} / \mathrm{s}\right)\end{array}$ & $\begin{array}{l}\text { Concentration } \\
(\mathrm{ppm})\end{array}$ & $\begin{array}{l}\text { Time } \\
\text { (min) }\end{array}$ & $\begin{array}{l}\text { Radius } \\
\text { (m) }\end{array}$ & $\begin{array}{c}\text { Diffusion } \\
\text { coefficient } \\
\left(\times 10^{3} \mathrm{~cm}^{2} / \mathrm{s}\right)\end{array}$ \\
\hline 0.7 & 19 & $16 \cdot 1$ & & $10 \cdot 0$ & 44 & 16.5 & \\
\hline 0.5 & 19 & $26 \cdot 1$ & $2 \cdot 7$ & $5 \cdot 0$ & 44 & 25.9 & 0.5 \\
\hline $0 \cdot 1$ & 19 & $49 \cdot 4$ & $2 \cdot 4$ & $3 \cdot 0$ & 44 & $39 \cdot 7$ & $1 \cdot 3$ \\
\hline 0.4 & 50 & $10 \cdot 2$ & & $0 \cdot 2$ & 104 & 45.6 & \\
\hline 0.3 & 50 & $17 \cdot 8$ & $0 \cdot 6$ & $0 \cdot 1$ & 104 & 63.9 & $1 \cdot 1$ \\
\hline 0.2 & 50 & $31 \cdot 2$ & $1 \cdot 3$ & 0.05 & 104 & 83.5 & 1.7 \\
\hline 0.05 & 50 & $58 \cdot 1$ & 1.4 & & & & \\
\hline 0.18 & 61 & $21 \cdot 3$ & & 0.08 & 162 & $50 \cdot 8$ & \\
\hline $0 \cdot 15$ & 61 & $29 \cdot 3$ & 1.5 & 0.03 & 162 & $121 \cdot 2$ & 3.2 \\
\hline $0-10$ & 61 & $41 \cdot 5$ & 1.4 & & & & \\
\hline
\end{tabular}

Table 3. Computed diffusion coefficients (expressed as $\mathrm{cm}^{2} / \mathrm{s}$ ) after the releases at D-3 and D.4.

\begin{tabular}{|c|c|c|c|c|c|c|c|}
\hline \multicolumn{4}{|c|}{$\begin{array}{c}\text { Release at } \mathrm{D}-3 \\
\text { Initial } \text { mass released }=500 \mathrm{~g}\end{array}$} & \multicolumn{4}{|c|}{$\begin{array}{c}\text { Release at } \mathrm{D}-4 \\
\text { Initial } \text { mass released }=500 \mathrm{~g}\end{array}$} \\
\hline $\begin{array}{l}\text { Concentration } \\
\quad(p p m)\end{array}$ & $\begin{array}{l}\text { Time } \\
(\mathrm{min})\end{array}$ & $\begin{array}{l}\text { Radius } \\
\text { (m) }\end{array}$ & $\begin{array}{c}\text { Diffusion } \\
\text { coefficient } \\
\left(\times 10^{3} \mathrm{~cm}^{2} / \mathrm{s}\right)\end{array}$ & $\begin{array}{l}\text { Concentration } \\
\text { (ppm) }\end{array}$ & $\underset{(\min )}{\text { Time }}$ & $\begin{array}{l}\text { Radius } \\
\text { (m) }\end{array}$ & $\begin{array}{c}\text { Diffusion } \\
\text { coefficient } \\
\left(\times 10^{3} \mathrm{~cm}^{2} / \mathrm{s}\right)\end{array}$ \\
\hline 1.0 & 40 & 13.4 & & 1.5 & 26 & $22 \cdot 7$ & \\
\hline 0.5 & 40 & $18 \cdot 7$ & 0.3 & $1 \cdot 0$ & 26 & $35 \cdot 2$ & 2.8 \\
\hline 0.1 & 40 & $26 \cdot 6$ & 0.2 & 0.5 & 26 & $43 \cdot 3$ & 1.5 \\
\hline 0.5 & 82 & $15 \cdot 5$ & & 0.4 & 68 & $18 \cdot 7$ & \\
\hline 0.3 & 82 & 24.9 & 0.4 & $0 \cdot 3$ & 68 & $27 \cdot 3$ & 0.8 \\
\hline 0.2 & 82 & $38 \cdot 2$ & 1.0 & 0.2 & 68 & 37.5 & 1.0 \\
\hline $0 \cdot 1$ & 82 & $55 \cdot 0$ & $1 \cdot 1$ & 0.1 & 68 & $63 \cdot 7$ & $2 \cdot 3$ \\
\hline 0.1 & 135 & $31 \cdot 3$ & & 0.15 & 125 & $23 \cdot 5$ & \\
\hline 0.08 & 135 & $50 \cdot 5$ & $2 \cdot 1$ & 0.12 & 125 & $29 \cdot 9$ & 0.5 \\
\hline \multirow[t]{2}{*}{0.06} & 135 & $61 \cdot 3$ & $1 \cdot 3$ & 0.10 & 125 & $42 \cdot 2$ & 1.6 \\
\hline & & & & 0.05 & 125 & $67 \cdot 3$ & $1 \cdot 3$ \\
\hline
\end{tabular}

was made during ebb, whereas at D-2 it was during flood tide. In the former case, the dye patch moved northward and in the latter case, the displacement was in the southward direction. At D-3 and D-4, the release occurred during slack. So, the movements of the patches had been slow in either case. In these two cases, the patches got advected westward. At D-1 and D-2, the computed diffusion coefficients were higher than those at D-3 and D-4, with the exception of the values found during the first time interval of tracing at D-4. This probably suggests that when the dye patches got advected in the alongshore direction (north-south), the diffusion rates were higher 
than when the movements of patches occurred in the cross-shore direction (west).

The following points can be noted from the values of computed diffusion coefficients. Except in the first time interval of tracing at D-1 and D-4, with increase of time the diffusion coefficients also increase. This was reported by previous workers when the time scale is short. In addition, it was found that for a given time interval of tracing, i.e., for a given distribution, diffusion coefficients increase as the radius of the patch increases. There have not been many earlier studies to estimate the diffusion coefficients in the Indian coastal waters for making possible comparisons with our results. Officer (1976) summarized the results of dye diffusion experiments using Rhodamine-B conducted in different estuaries and coastal regions. For the time interval of tracing of about $2-5 \mathrm{~h}$, the values of the diffusion coefficients are of the order of $10^{3}-10^{4} \mathrm{~cm}^{2} / \mathrm{s}$. For time scales of $>10 \mathrm{~h}$ of the dye release and tracing, these values increased by an order of magnitude than those obtained for shorter time scales. The present values of diffusion coefficients do agree with these results.

\section{Conclusion}

The present work enabled us to determine the diffusion rates of a passive dye at four different places near the mouth of the Kakinada Bay. Based on the information obtained from our study, the following points have to be considered while choosing a suitable outfall location. (i) Discharges during ebb minimize the risks of the effluents entering into the Bay, as evidenced in the case of release at D-1. (ii) Locations near the eastern part of the mouth of the Bay must be avoided for discharges, as they are likely to get recirculated due to the clockwise gyre type of circulation. This was found in the case of D-2 release. (iii) When the patches got advected in the north-south direction, their movements and diffusion rates were higher than when movements of dye patches occurred westwards.

The values of diffusion coefficients were found to lie between $0.2 \times 10^{3} \mathrm{~cm}^{2} / \mathrm{s}$ and $2.9 \times 10^{3} \mathrm{~cm}^{2} / \mathrm{s}$. There is hardly any information in the literature regarding these coefficients in the coastal waters in this region for making comparison with our results. However, the order of magnitude of diffusion coefficients now obtained agrees with earlier results for the corresponding length and time scales.

More precise information than that obtained in the present study requires development of a two-dimensional model for the circulation and diffusion.

\section{Acknowledgements}

We are grateful to Engineers India Limited, New Delhi for allowing us to participate in their surveys and providing the data. We thank Dr J Subba Rao, JNU for useful discussions.

\section{References}

Joseph J and Sendner H 1958 Uber die horizontale Diffusion inm Meere; Dtsch. Hydrogr. Z. 11 39-77

Kullenberg G 1968 Measurements of horizontal and vertical diffusion in coastal waters; Report of Institute for Physical Oceanography, University of Copenhagen Vol. 3, pp. 55 
Okubo A 1962 Horizontal diffusion from an instantaneous point source due to oceanic turbulence; Chesapeake Bay Institute Report 32123

Officer C B 1976 Physical oceanography of Estuaries (New York: Wiley Interscience) pp. 465

Rama Sarma D V and Ganapati P N 1968 Hydrography of the Kakinada Bay; Bull. Natl. Inst. Sci. India 38 $49-79$

Salomon J C 1980 Etude de l'estuaire de la Seine. Modelisation numerique des phenomenes physiques; Rapport provisoire. Universite de Bretagne Occidentale, Brest, France 